\title{
Detection of Microbial Degradation of Natural Rubber Latex by Isolated Native Bacteria in Sri Lanka
}

\author{
G.Y. Liyanage, P.M. Manage* \\ Department of Zoology, University of Sri Jayewardenepura, Sri Lanka \\ *pathmalalmanage@gmail.com
}

\begin{abstract}
Rubber waste management plays an important role to deal with high production and consumption of rubber. The main constituents of natural rubber is cis 1,4-polyisoprene. It is relatively resistant to microbial decomposition compared with many other natural polymers. The aim of study was to evaluate the potential effects of the Bacillus cereus, Enterobacter sp. and Enterobacter ludwigii on natural rubber latex degradation. Aliquots of $100 \mathrm{ml}$ mineral salt medium were prepared and latex was spiked at different concentrations to make final dilutions at 1:10,000, 1:15,000. Each isolates were separately inoculated $(3 \% \mathrm{v} / \mathrm{v})$ to each dilution and incubated at $120 \mathrm{rpm}$ for 12 days. Pour plate method was performed to confirm the resistance of bacteria against to latex. The amount of $\mathrm{CO}_{2}$ liberation was determined during the cultivation of cells in mineral salt medium and the released $\mathrm{CO}_{2}$ was trapped by $1 \mathrm{M} \mathrm{NaOH}$. Quantification of $\mathrm{CO}_{2}$ was performed by titrimetric method. The liberation of $\mathrm{CO}_{2}$ was gradually increased and reached at 8.67, 9.78 and $10.31 \mathrm{ppm}$ for E.ludwigii, B.cereus and Enterobacter sp. respectively. $\mathrm{CO}_{2}$ liberation was not detected in control. Based on the calculation adapted to the present study, $100 \%$ of latex degradation of latex by released $\mathrm{CO}_{2}$ value should equal to $12.5 \mathrm{ppm}$. The present study showed that B.cereus, E. ludwigii and Enterobacter sp. have harber gene which can produce enzyme to degrade latex and future studies are needed to elucidate the degradation mechanism.
\end{abstract}

Keywords: Natural Rubber Latex, E.ludwigii, B. cereus, Enterobacter sp. 